\title{
Time-resolved reaction studies on the atomic scale: NO and CO adsorption on stepped Rh surfaces
}

Cite as: Journal of Vacuum Science \& Technology A 8, 3432 (1990); https://doi.org/10.1116/1.576527 Submitted: 11 December 1989 . Accepted: 07 February 1990. Published Online: 04 June 1998

N. Kruse

ARTICLES YOU MAY BE INTERESTED IN

Adsorption of $\mathrm{CO}$ on $\mathrm{Rh}(100)$ studied by infrared reflection-absorption spectroscopy The Journal of Chemical Physics 93, 8328 (1990); https://doi.org/10.1063/1.459316

The molecular and atomic states of oxygen adsorbed on Rh(100): Adsorption Journal of Vacuum Science \& Technology A 1, 1064 (1983); https://doi.org/10.1116/1.572044

Pattern formation during the CO-oxidation involving subsurface oxygen

Chaos: An Interdisciplinary Journal of Nonlinear Science 12, 157 (2002); https://

doi.org/10.1063/1.1448809

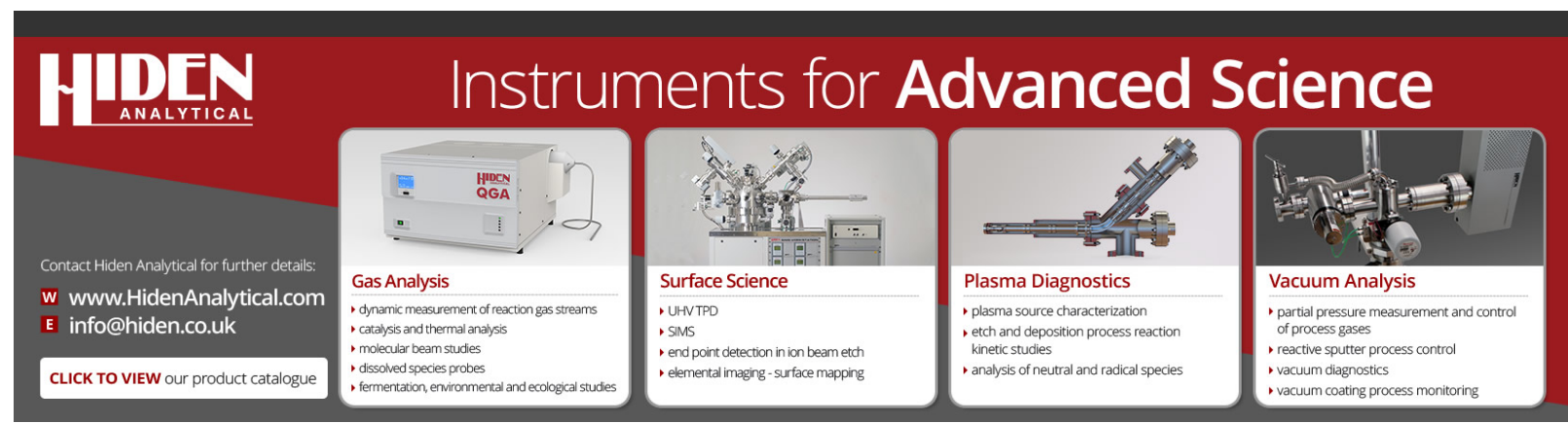




\title{
Time-resolved reaction studies on the atomic scale: $\mathrm{NO}$ and $\mathrm{CO}$ adsorption on stepped Rh surfaces
}

\author{
N. Kruse \\ Technisch-Chemisches Laboratorium, ETH-Zentrum, 8092 Zürich, Switzerland and Fritz-Haber-Institut \\ der Max-Planck-Gesellschaft, Faradayweg 4-6, D-1000 Berlin 33, Federal Republic of Germany
}

(Received 11 December 1989; accepted 7 February 1990)

\begin{abstract}
The interaction of $\mathrm{NO}$ and $\mathrm{CO}$ with stepped surfaces of $\mathrm{Rh}$ field emitter tips has been studied by means of pulsed field desorption mass spectrometry (PFDMS) at temperature $300<T<600 \mathrm{~K}$ and steady gas pressures $p<1.3 \times 10^{4} \mathrm{~Pa}$. The repetition frequency of the pulses, i.e., the field free reaction time $t_{R}$ between the pulses has been varied in the range $100 \mu \mathrm{s} \leqslant t_{R} \leqslant 1 \mathrm{~s}$ in order to obtain information about the kinetics of surface reactions. The pulsed field desorption (PFD) mass spectra obtained during $\mathrm{NO}$ adsorption always contain $\mathrm{NO}^{+}, \mathrm{Rh}_{x} \mathrm{~N}^{n+}$, and $\mathrm{RhO}^{n+}$ ions $(x, n=1,2)$. This finding suggests that part of the adsorbed NO undergoes dissociation during $t_{R}$. For short reaction times, i.e., low surface coverages, NO adsorption is found to be predominantly molecular. Using a probe hole $\sim 150$ atomic sites close to the (100) pole of the tip surface have been analyzed in detail. The equilibration between adsorption and thermal desorption of NO has been monitored by $t_{R}$ variation. In this manner the mean lifetimes $\tau$ before first order thermal desorption can be determined. From the temperature dependence of the $\tau$ values the thermal desorption kinetics have been evaluated. An activation energy $E_{d}=102 \mathrm{~kJ} / \mathrm{mol}$ and a preexponential $\tau_{0}=3 \times 10^{\text {it }} \mathrm{s}$ are found. The PFD mass spectra obtained during CO adsorption on stepped $\mathrm{Rh}$ planes contain $\mathrm{CO}^{+}$and $\mathrm{Rh}(\mathrm{CO})_{y}^{n+}$ ions $(n=1,2 ; y=1-3)$. The $t_{R}$ dependence of these species has been measured and found to be consistent with a consecutive surface reaction between chemisorbed $\mathrm{CO}$ and $\mathrm{Rh}$ step atoms leading to adsorbed $\mathrm{Rh}$ subcarbonyls. Possibly $\mathrm{Rh}-\mathrm{Rh}$ bonds are broken during $\mathrm{Rh}(\mathrm{CO})_{2}$ formation so that this species is liberated and able to diffuse into the terrace regions of the surface. Only a small amount of adsorbed $\mathrm{CO}$ undergoes dissociation at long reaction times.
\end{abstract}

\section{INTRODUCTION}

Scanning tunneling microscopy (STM) is currently generating increasing interest in investigations of gas-surface interactions on the atomic scale. 'The real space imaging of coadsorbed $\mathrm{CO}$ and benzene on $\mathrm{Rh}(111)$ is one of the illuminating examples proving that a definitive identification of different molecules on a single crystal surface is possible by STM. ${ }^{2}$ Another experimentally different approach which can be used to study the interactions of species in adsorbed layers is pulsed field desorption mass spectrometry (PFDMS), which is basically similar to the time-of-flight atom probe originally developed by Müller. ${ }^{3}$ In a number of investigations PFDMS has proven its ability to identify the chemical nature of species formed in complex overlayers during adsorption from the gas phase (e.g., Refs. 4, 5). In addition, the kinetics of reaction processes in these overlayers can be investigated when the repetition frequency of the desorbing field pulses (i.e., the time between any two pulses) is systematically varied. In this manner, only a few up to $\sim 200$ atomic sites of a crystallographically well defined surface are probed.

This paper reports on results obtained for the interaction of NO and CO with $\sim 150$ atomic sites of a stepped Rh surface containing ( 100$)$ oriented terraces. The NO part of our study has been prompted by the partly controversial results described in the literature. DeLouise and Winograd ${ }^{6}$ studied NO adsorption on $R h(331)$ and $R h(111)$ by means of $x$-ray photoelectron spectroscopy (XPS) and secondary ion mass spectrometry (SIMS). At saturation coverage, the authors found $\sim 10$ times more dissociated species on the stepped (331) surface at $300 \mathrm{~K}$ than on the atomically flat (111) surface. However, Dubois et al., ${ }^{7}$ in a study of NO interaction with $R h(331)$ by means of high-resolution electron energy loss spectroscopy (HREELS), could not detect any $\mathrm{NO}_{\text {ad }}$ dissociation at $300 \mathrm{~K}$.

Temperature programmed desorption (TPD) studies employing low index (100) and (111) oriented $\mathrm{Rh}$ surfaces revealed NO dissociation during heating. ${ }^{8-12}$ The dissociation process was complete provided the initial $\mathrm{NO}_{\mathrm{ad}}$ coverage was small enough. The PFDMS data to be presented here demonstrate that molecular and dissociative chemisorption of NO on stepped $\mathrm{Rh}(100)$ are competing processes. A kinetic analysis of the thermal desorption of $\mathrm{NO}_{\mathrm{ad}}$ at low coverages will be given.

$\mathrm{CO}$ adsorption on stepped $\mathrm{Rh}$ single crystal surfaces has not been the subject of many studies to date. ${ }^{13-15}$ Recently, the formation of adsorbed $\mathrm{Rh}(\mathrm{CO})_{x}(x=1-3)$ has been observed $^{14,15}$ and ascribed to a consecutive surface reaction of $\mathrm{CO}_{\mathrm{ad}}$ with $\mathrm{Rh}$ step atoms. ${ }^{15}$ The present paper provides data of the time dependence of this reaction process.

\section{EXPERIMENTAL}

\section{A. General}

Both the experimental setup required for PFDMS and its application to kinetic studies of surface reactions have been described in detail elsewhere. ${ }^{16,17}$ In brief, short pulses 
(widths $\geqslant 100 \mathrm{~ns}$, repetition rates $\leqslant 100 \mathrm{kHz}$ ) of high electric field strengths $(\leqslant 50 \mathrm{~V} / \mathrm{nm})$ are applied to a counter electrode ( with a hole), mounted at a distance of $0.1 \mathrm{~mm}$ in front of a field emitter. While continuously dosing the emitter surface by the gaseous reactants, adsorbed species are desorbed as ions which are separated and detected according to their mass-to-charge ratio by time-of-flight measurements. Thus, information about the chemical composition of the adsorbed layer is obtained. A channel plate image intensifier with a probe hole is mounted at the entrance of the flight tube and allows us to determine the crystallographic orientation of the tip, e.g., by field electron microscopy at reversed fields. The tip can be tilted in front of the hole in the channel plate in order to probe crystallographically different planes containing up to $\sim 200$ atomic sites.

In the time $t_{R}$, between the pulses, an arbitrary base (dc) field can be maintained. For the measurements to be reported here, a dc field was not applied. A systematic variation of the dc field from the onset of electron emission (at reversed fields) up to the onset of field ionization allows us to determine the influence of the electric field on the reaction processes in the adsorbed layer. Rh field emitter tips were prepared by etching a $0.1 \mathrm{~mm}$ diameter wire of $99.9 \%$ purity in molten $\mathrm{NaCl} / \mathrm{NaNO}_{2}$ salt solution $(1: 4 \mathrm{w} / \mathrm{w})$. The specimens were cleaned in situ by combined cycles of field evaporation and heating in hydrogen. NO of $99.8 \%$ purity was provided by Messer Griesheim and used without further purification. Surface temperatures were measured by a thermocouple spotwelded to the shank of the emitter tip.

\section{B. Kinetic measurements}

Kinetic data of surface processes can only be obtained if the adsorbed layer is completely desorbed by the field pulses. This requirement is checked by field strength variation: while dosing the emitter surface continuously by $\mathrm{NO}$ or $\mathrm{CO}$, the field pulse amplitudes are gradually raised. This leads to increasing ion intensities and, consequently, to the depletion of the adsorbed layer. Above a certain value of the desorption field strength the ion intensities reach a maximum and do not increase any further. Under these conditions field desorption is complete. Provided the fragmentation patterns of the adsorbed species are known (obtained from dc field strength variation) the measured intensities represent surface concentrations within the monitored area before a pulse.

Figure 1 illustrates, schematically, how the concentration of an adsorbed species develops with increasing reaction times. Adsorption takes place only in the time $t_{R}$ between the pulses. At the end of $t_{R}$, the adsorbed layer is completely desorbed by a field pulse so that the next reaction period has again the starting condition of zero coverage. As indicated on the left of Fig. 1 the surface concentration that is reached for short reaction times is far below any saturation or equilibrium limit. Under these conditions the probability of consecutive surface reactions is low and, consequently, the field pulses probe the initial stages of the adsorption process. The longer the reaction time, the more the adsorption process proceeds. Thus, the kinetics of the adsorption process can be

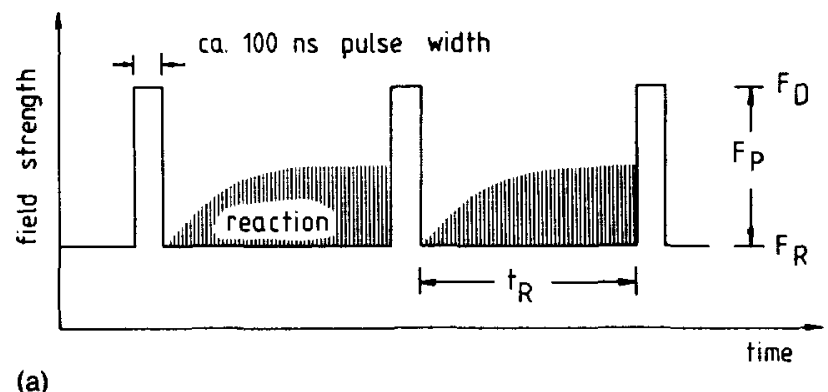

(a)
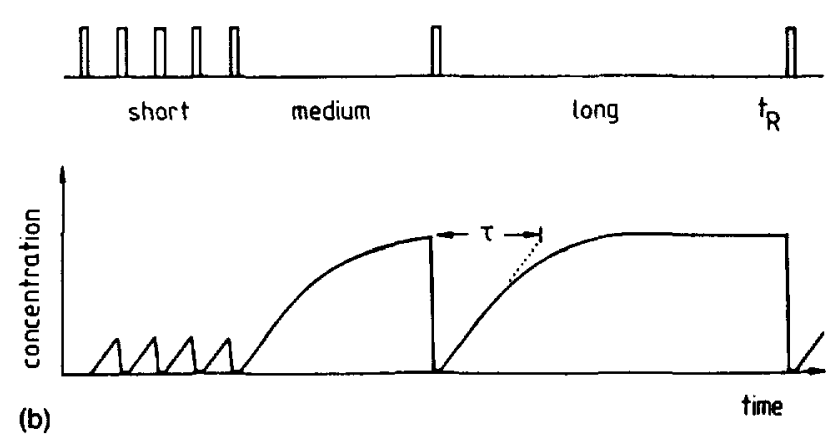

FIG. 1. (a) Time scheme of the desorption field pulses $F_{D}$ : desorption field strength; $F_{R}$ : arbitrary base field strength during the reaction interval $t_{R}$ (b) Development of surface concentration for different pulse repetition frequencies.

monitored by the systematic variation of $t_{R}$, which is usually done in the range $100 \mu \mathrm{s} \leqslant t_{R} \leqslant 1 \mathrm{~s}$.

Provided the temperature is chosen appropriately, a steady surface layer can be established for long reaction times. In this case the ionic intensity and, consequently, the surface concentration does not increase further with $t_{R}$, as indicated on the right of Fig. 1. A systematic variation of the reaction time allows one to determine the relaxation time $\tau$, characteristic for the formation of a steady layer.

In the NO part of our study it has been found that the steady surface concentration that builds up at long reaction times is due to thermal desorption counteracting adsorption from the gas phase. If adsorption occurs with a constant sticking probability and thermal desorption obeys first order kinetics, i.e., $d c / d t=-c / \tau$, then the surface concentration develops according to

$$
c=\hat{c}\left(1-e^{-t / \tau}\right) \text {, }
$$

where the relaxation time $\tau$ is the mean lifetime before thermal desorption. According to Eq. (1), $\tau$ is equal to the value of $t_{R}$ when the $(1-1 / e)$ level of the steady surface concentration $\hat{c}$ is reached. The temperature dependence of $\tau$ can be parametrized via Frenkel's equation,

$\tau=\tau_{0} \cdot e^{E_{d \prime} / k \tau}$.

Both the activation energy $E_{d}$ for thermal desorption and the preexponential $\tau_{0}$ are accessible in this way.

\section{RESULTS AND DISCUSSIONS}

\section{A. NO/Rh}

The results presented here have been obtained by probing $\sim 150$ atomic sites of the stepped surface region close to the 
(100) pole of a $\mathrm{Rh}$ field emitter. The surface was continuously dosed at a steady NO gas pressure of $1.3 \times 10{ }^{5} \mathrm{~Pa}$. Figure 2 presents a typical time-of-flight mass spectrum obtained with a field strength $F_{D}=28 \mathrm{~V} / \mathrm{nm}$ (pulses only, no base field), which turned out to be high enough to keep the surface dynamically clean. Under these conditions field evaporation of the substrate material takes place as evidenced by the occurrence of $\mathrm{Rh}^{+}$and $\mathrm{Rh}^{+}+$ions.

As is clearly seen in Fig. 2, the mass spectrum is dominated by $\mathrm{NO}^{+}$ions. It is concluded that the surface layer contains mainly molecularly adsorbed $\mathrm{NO}$ at a reaction temperature of $T=547 \mathrm{~K}$. The small amount of $\mathrm{RhNO}^{+}$ions possibly indicates field desorption of $\mathrm{NO}_{\mathrm{ad}}$ from step sites with the simultaneous removal of a $\mathrm{Rh}$ step atom. The maximum $\mathrm{NO}_{\text {acl }}$ concentration built up during $t_{R}=200 \mu \mathrm{s}$ was below $10^{+}$monolayer. Moderate intensities are found for $\mathrm{RhO}^{+}{ }^{+}, \mathrm{RhN}^{+}{ }^{,}, \mathrm{Rh}_{2} \mathrm{~N}^{+}+$, and $\mathrm{RhO}^{+}$. Also $\mathrm{O}^{+}, \mathrm{N}^{+}$, and $\mathrm{O}_{2}{ }^{\prime}$ ions can be detected, however, under the conditions applied in Fig. 2 their intensities are lower than those of the above mentioned species. It is concluded that $\mathrm{NO}_{\mathrm{ad}}$ has undergone partial dissociation during $t_{R}$, so that oxygen and nitrogen atoms are deposited on the surface. This result is in agreement with the catalytic behavior known for the $\mathrm{Rh}$ metal. It is interesting that the products of $\mathrm{NO}_{\mathrm{ad}}$ dissociation are mainly field desorbed along with the removal of $\mathrm{Rh}$ (step) atoms. However, the conclusion that dissociation occurs directly at step sites is not straightforward on the basis of Fig. 2 alone. If terrace sites are also active, diffusion of nitrogen and oxygen atoms could occur with subsequent trapping and field desorption at step sites. On the other hand, assuming that step rather than terrace sites are active in $\mathrm{N}-\mathrm{O}$ bond breaking under our experimental conditions, a strong face dependence of this process is expected. In fact, surface areas with higher step site densities than probed here have been found to produce larger amounts of dissociation products. These measurements are still in progress and the results will be the subject of a future publication. High activity of step sites in $\mathrm{N}-\mathrm{O}$ bond scisson has also been observed in work performed on macroscopic stepped single crystal

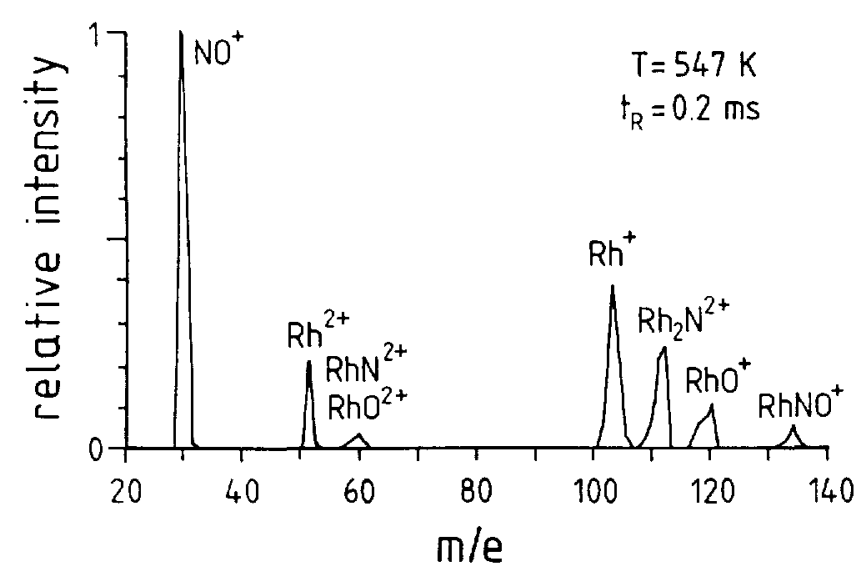

FIG. 2. Time-of-flight mass spectrum of NO on stepped $\mathbf{R h}$ with (100) orientation of the terraces; NO pressure: $1.3 \times 10^{5} \mathrm{~Pa}$; desorption field $F_{D} \approx 28 \mathrm{~V} / \mathrm{nm}$; no base field $\left(F_{k}=0\right)$; temperature $T=547 \mathrm{~K}$. surfaces. ${ }^{6.13}$ Hendrickx and Nieuwenhuys performed reaction studies with $\mathrm{Rh}$ field emitter tips and provided an activity pattern of the various planes towards $\mathrm{NO}_{\mathrm{ad}}$ dissociation. ${ }^{18}$ The high index planes were found to decompose $\mathrm{NO}_{\mathrm{ad}}$ most easily. In particular, Rh (321) and (322) exhibited the highest decomposition activity.

Our results are qualitatively in line with those cited above. However, it should be emphasized that, according to the present study, molecular adsorption of NO dominates over dissociation even at $T=547 \mathrm{~K}$ and very low surface coyerages $\left(\Theta_{\mathrm{NO}}<10^{-4}\right.$ monolayer, see above). This result which also holds when probing the stepped surface region close to the (111) plane, is in contrast to most of the results obtained with macroscopic single crystal surfaces ${ }^{6,8-10,12}$ which revealed complete dissociation of small $\mathrm{NO}_{\mathrm{ac}}$ concentrations during heating from low temperatures to above $300 \mathrm{~K} . \mathrm{N}_{2}$ and $\mathrm{O}_{2}$ (due to recombination reactions), rather than NO thermal desorption, were observed in these investigations. Obviously, $\mathrm{NO}_{\text {ad }}$ dissociation on $\mathrm{Rh}$ is a rather slow process which occurs to only a relatively small extent during the short reaction time $t_{R}=200 \mu$ s of our experiment, but is complete in a TPD measurement with a time constant of the order of some $10 \mathrm{~s}$. This conclusion is supported by the observation that the amount of dissociation products increased with increasing $t_{R}$ values. Although the detailed dissociation kinetics investigated by PFDMS will be presented elsewhere, it should be mentioned here that the ionic intensities of the oxide and nitride species exhibit a nearly second order time dependence. This result shows that fragmentation of the $\mathrm{NO}_{\mathrm{ad}}$ during the field pulses cannot play a significant role. Rather we have to assume that a consecutive surface reaction takes place in which NO adsorption occurs first and chemical dissociation subsequently.

We will now focus on the thermal desorption kinetics of $\mathrm{NO}_{\mathrm{ad}}$. For this purpose we followed the procedure described in the experimental part of the paper and varied the reaction time $t_{R}$ from $100 \mu \mathrm{s}$ to $1 \mathrm{~s}$ at various temperatures between 443 and $547 \mathrm{~K}$. The mean lifetimes $\tau$ before thermal desorption were taken to be the values of $t_{R}$ for which the $63 \%$ level of the steady surface coverages were reached. The temperature dependence of the $\tau$ values was evaluated according to Frenkel's Eq. (2) and plotted in Fig. 3 as $-\ln \tau$ versus $1 / T$. An activation energy $E_{d}=102 \mathrm{~kJ} / \mathrm{mol}$ was obtained from the slope and a preexponential value of $\tau=4 \times 10^{14} \mathrm{~s}$ from the intersect with the ordinate. These values are in reasonable agreement with those reported in the literature for NO on $\mathrm{Rh}(100){ }^{9.11 .12}$ For example, Villarrubia and $\mathrm{Ho}^{12}$ determined $E_{c}=118 \mathrm{~kJ} / \mathrm{mol}$ and $\tau_{0}=10^{14} \mathrm{~s}$ by temperature programmed electron energy loss spectroscopy (TP-EELS) with varying heating rates and an initial surface concentration $\Theta_{0}=0.5$ monolayer which is about two orders of magnitude larger than the maximum value reached at the lowest temperature in our experiments $(T=443 \mathrm{~K})$. The relatively high $\Theta_{0}$ value was found necessary in order to prevent complete dissociation of the adsorbed layer during heating. ${ }^{12}$ Nevertheless, once thermal desorption of $\mathrm{NO}_{\text {ild }}$ began, decomposition followed immediately at the emptied sites. In this manner more than $50 \%$ of the layer decomposed in the TPD experiment. Though decomposition occurs also under

J. Vac. Sci. Technol. A, Vol. 8, No. 4, Jul/Aug 1990 


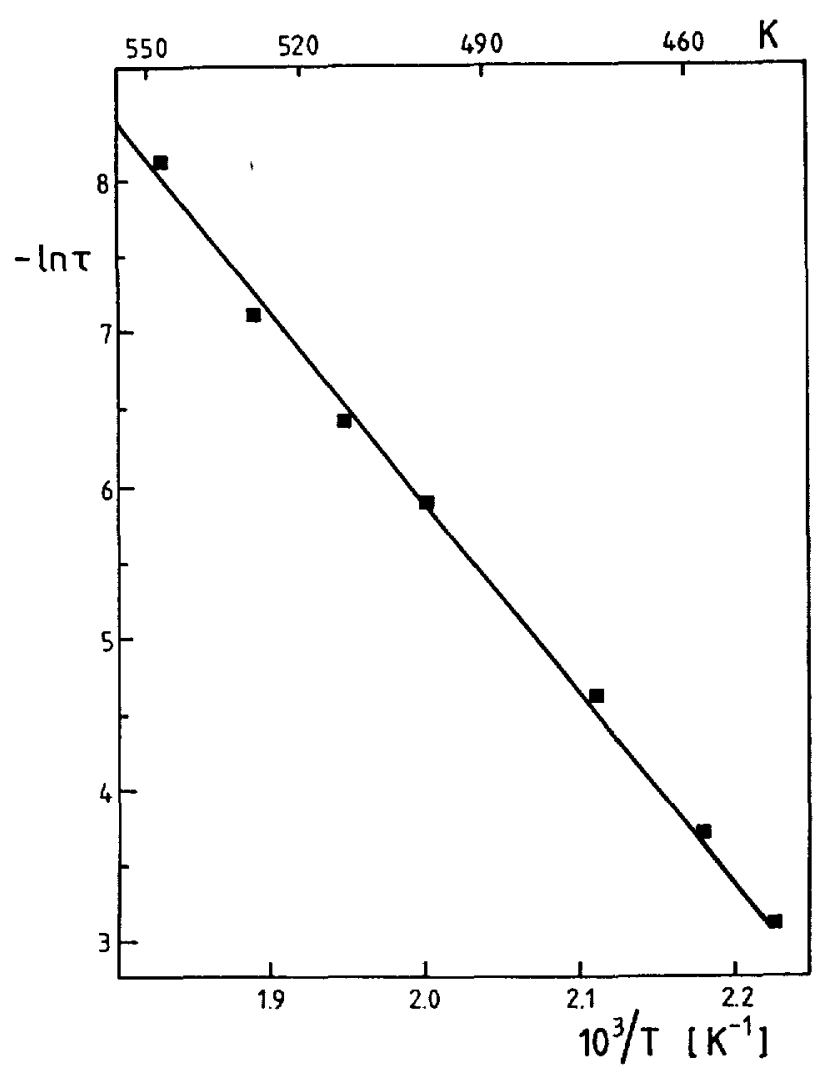

FIG. 3. Temperature dependence of the mean lifetimes $\tau$ of NO on the same tip as in Fig. 2

our isothermal reaction conditions, an influence on the desorption kinetics is unlikely since the products do not accumulate on the surface but are field desorbed by the pulses. In view of the similar rate data obtained in PFDMS with a stepped $R h(100)$ surface and in TPD/TP-EELS with macroscopic (100) single crystal surfaces ${ }^{9,11,12}$ it seems likely that $\mathrm{NO}_{\mathrm{ad}}$ desorption is not strongly affected by mutual interactions of species in the adsorbed layer and/or atomic steps which, in principle, could act as trapping and reaction sites. Future PFDMS work will address this point in more detail.

It is interesting to compare these results with those obtained previously for $\mathrm{NO}_{\mathrm{ad}}$ desorption from stepped $\mathrm{Pt}$ (111) surfaces, ${ }^{17}$ where the step sites, though present to only $\sim 12 \%$ on the field emitter surface, dominated the thermal desorption kinetics via intermediate (nondissociative) trapping of $\mathrm{NO}_{\mathrm{ad}}$. In the present study the stepped $\mathrm{Rh}(100)$ surface was found to be more active in $\mathrm{N}-\mathrm{O}$ bond breaking than any other stepped $\mathrm{Pt}$ field emitter surface probed before. Nevertheless, $\mathrm{NO}_{\mathrm{ad}}$ dissociation on $\mathrm{Rh}$ was not fast enough to saturate the steps with $\mathrm{N}_{\mathrm{ad}}$ and $\mathrm{O}_{\mathrm{ad}}$ and to provoke site blocking effects. It should also be mentioned that the dc field induced formation of $\mathrm{N}_{2} \mathrm{O}^{+}, \mathrm{N}_{2}^{+}$, and $\mathrm{O}^{+}$ions during interaction of NO with stepped $\mathrm{Pt}(111)$ surfaces $^{19}$ has as yet not been found to occur on stepped $\mathrm{Rh}$ surfaces.

\section{B. CO/Rh}

Adsorption and reaction of $\mathrm{CO}$ with $\mathrm{Rh}$ has been studied by probing $\sim 150$ atomic sites of the stepped region close to the (100) pole of the emitter tip. The measurements have been performed by continuously dosing $\mathrm{CO}$ to the tip at a pressure of $1.3 \times 10^{-4} \mathrm{~Pa}$ and at a temperature $T=298 \mathrm{~K}$. Various ionic species, including $\mathrm{CO}^{+}$and $\mathrm{Rh}(\mathrm{CO})_{x}^{n+}$ $(x=1-3, n=1,2)$ are seen in the resulting mass spectra indicating that a reaction leading to the formation of adsorbed $\mathrm{Rh}$ subcarbonyls takes place on the surface.

In a recent paper the influence of the desorption field strength on the ion intensities of the various species has been described in detail. ${ }^{15}$ Here we present data from reaction time variation measurements ( $\left.1 \mathrm{~ms} \leqslant t_{R} \leqslant 0.1 \mathrm{~s}\right)$ obtained at a desorption field, $F=28 \mathrm{~V} / \mathrm{nm}$, pulses of which are sufficient to desorb the adsorbed layer completely. ${ }^{15}$ Under these conditions the ion intensities represent surface concentrations of the various species in the monitored area.

As is seen in Fig. 4 the concentration of $\mathrm{CO}_{\text {chem }}$ (measured in form of $\mathrm{CO}^{+}$and $\mathrm{RhCO}^{+}+$ions, for details see Ref. 15) increases proportionally with $t_{R}$. Thus, the adsorption process occurs with a constant rate. This is expected since the total surface concentration is far below the monolayer limit, so that chemisorption occurs according to the

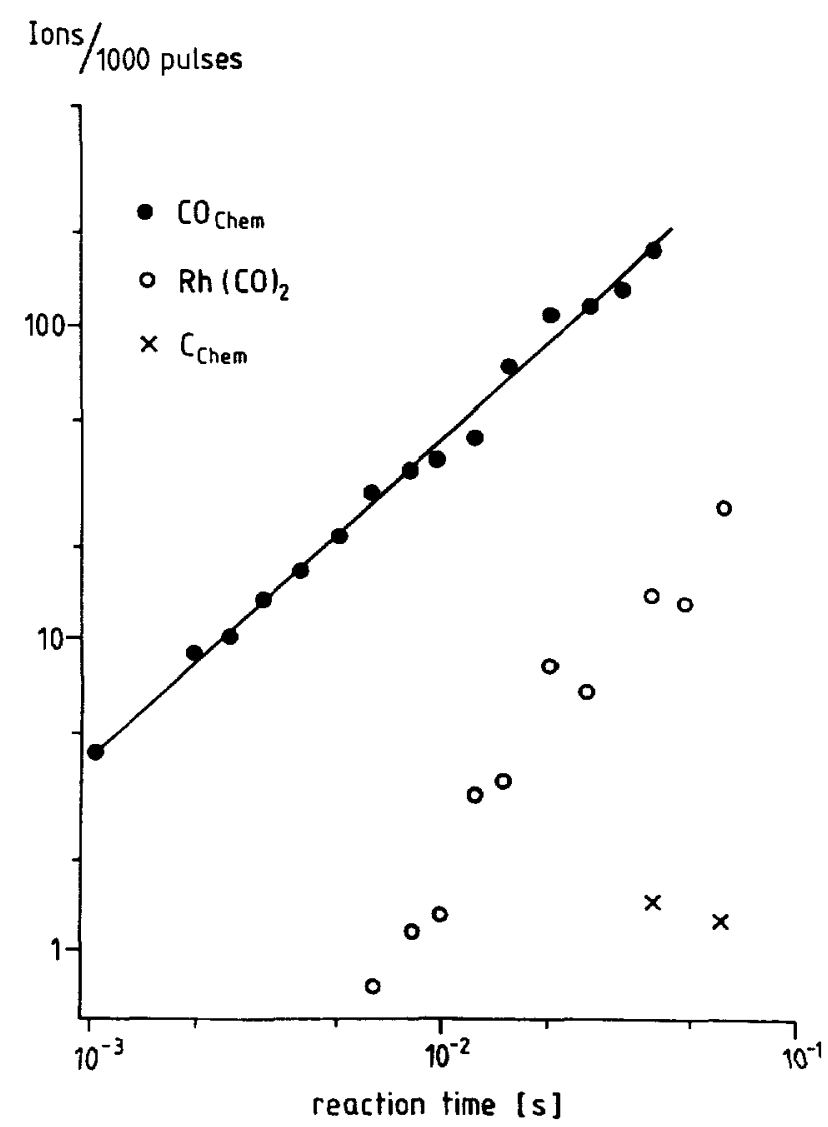

FIG. 4. Variation of the reaction time for $\mathrm{CO}$ on $\mathrm{Rh} ; p_{\mathrm{CO}}=1.3 \times 10^{4} \mathrm{~Pa}$, $T=298 \mathrm{~K}, F_{D}=28 \mathrm{~V} / \mathrm{nm}$ (field pulses only, no base field)

\section{J. Vac. Scl. Technol. A, Vol. 8, No. 4, Jul/Aug 1990}


simple Langmuir model with a constant sticking probability of the impinging $\mathrm{CO}$ molecules. The $\mathrm{Rh}(\mathrm{CO})_{2}$ species (field desorbed mainly as a doubly charged ion) is much less abundant within the measured time range.

The $\mathrm{Rh}(\mathrm{CO})_{2}$ species appears with distinct intensities at reaction times $t_{R}>5 \mathrm{~ms}$ and is regarded as an intermediate in the consecutive surface reaction leading to $\mathrm{Rh}(\mathrm{CO})_{3}$. The tricarbonyl species is not observed here, but has been found when the $\mathrm{CO}_{\text {chem }}$ concentration reached values close to the monolayer limit. ${ }^{15}$

The initial increase of the $\mathrm{Rh}(\mathrm{CO})_{2}$ concentration with time is considerably steeper than proportional. This feature excludes the possibility that significant amounts of $\mathrm{Rh}(\mathrm{CO})_{2}$ species are formed during the field desorption event. Rather we assume a consecutive surface reaction with successive addition of two $\mathrm{CO}_{\text {chen }}$ species to a single $\mathrm{Rh}$ step atom. According to Fig. 4 it seems that the rate of $\mathrm{Rh}(\mathrm{CO})_{2}$ formation reduces slightly with increasing reaction times. This is probably caused by the partial decomposition to $\mathrm{CO}_{\text {chem. }}$.

In Ref. 15 we proposed a microscopic model which described the $\mathrm{Rh}(\mathrm{CO})_{2}$ formation as the reaction of adsorbed $\mathrm{CO}$ molecules with $\mathrm{Rh}$ step atoms. There are arguments to assume that $\mathrm{Rh}(\mathrm{CO})_{2}$ [and $\mathrm{Rh}(\mathrm{CO})_{3}$ ] is a mobile surface species. Clearly, $\mathrm{Rh}-\mathrm{Rh}$ bonds must be broken when these subcarbonyl species are liberated. For energetic reasons, a $\mathrm{Rh}$ kink site is the most likely position for this process. CO induced $\mathrm{Rh}-\mathrm{Rh}$ bond rupture was also observed in measurements of the extended $x$-ray absorption fine structure (EXAFS) of $\mathrm{Rh} / \mathrm{Al}_{2} \mathrm{O}_{3}$ model catalysts. ${ }^{20}$ Small supported $\mathrm{Rh}$ crystallites were seen to dissolve in the presence of $\mathrm{CO}$, ultimately leading to $\mathrm{Rh}$-dicarbonyl species atomically dispersed on the $\mathrm{Al}_{2} \mathrm{O}_{3}$ support.

In Ref. 15 we discussed possible implications that could arise in the case of $\mathrm{Rh}(\mathrm{CO})_{2}$ surface diffusion. One major point concerns its disturbing influence during kinetic measurements. It cannot be completely ruled out that mobile $\mathrm{Rh}(\mathrm{CO})_{2}$ species move into the monitored area during reaction time variation. A long range diffusion from the shank of the tip (where a saturated layer exists) towards its apex, however, can be suppressed by high field strengths: before arriving at the apex the $\mathrm{Rh}(\mathrm{CO})_{x}(x=2,3)$ may either decompose chemically (the surface layer is largely depleted) or desorb as ions due to the pulses.

In Fig. 4 it can be seen that $\mathbf{R h}(\mathrm{CO})_{2}$ formation occurs only after an incubation time. Obviously, a certain $\mathrm{CO}_{\text {chem }}$ concentration has to build up before any consecutive surface reaction takes place. Similar observations have also been made in studies of subcarbonyl formation of $\mathrm{Ni}^{21}$ and $\mathrm{Ru}^{5}$ In the case of $\mathrm{Ni}$ the incubation time coincided with the completion of a saturated (compressed) $\mathrm{CO}_{\text {chem }}$ layer. Satu- ration does not seem to be a prerequisite for the formation of subcarbonyls on $\mathrm{Rh}$ and $\mathrm{Ru}$. As seen in Fig. 4 the $\mathrm{Rh}(\mathrm{CO})_{2}$ production begins while $\mathrm{CO}$ chemisorption is still in progress. A steady $R h(C O)_{2}$ concentration is not achieved within the measured time range. This requires longer times than those used here and has only been observed after reaching the monolayer limit of $\mathrm{CO}_{\text {chem }}$.

Subcarbonyl formation does not only occur during $\mathrm{CO}$ interaction with stepped $\mathrm{Rh}, \mathrm{Ru}$, and $\mathrm{Ni}$ surfaces. Co and $\mathrm{Pd}$ surfaces are also active in this respect. On the other hand, $\mathrm{Fe}$ and Mo surfaces have as yet not been found capable of forming subcarbonyls under the experimental conditions applied in PFDMS. This is possibly due to an enhanced activity of these metals towards $\mathrm{CO}$ decomposition.

A small amount of carbon is found in Fig. 4 at long reaction times. This is possibly due to the decomposition of $\mathrm{CO}_{\text {chen }}$ at steps. The statistical significance of such a small amount of carbon is unclear, so a detailed discussion must await further experiments. Under the conditions employed here $\mathrm{Rh}(\mathrm{CO})_{2}$ formation at steps is always dominant, but this process could possibly be inhibited when large amounts of carbon block the step sites.

${ }^{1}$ R. J. Behm and W. Hösler, in: Chemistry and Physics of Solid Surfaces VI, edited by R. Vanselow and R. Howe (Springer, Berlin, 1986), p. 361 'S. Chiang, R. J. Wilson, C. M. Mate, and H. Ohtani, J. Microsc. (Oxford), 152, 567 (1988).

'E. Müller, J. A. Panitz, and S. B. McLane, Rev. Sci. Instrum. 39, 83 (1968).

${ }^{4}$ N. Kruse, G.-K, Chuah, G. Abend, D. L. Cocke, and J. H. Block, Surf. Sci. 189/190, 832 (1987).

'N. Kruse, Surf. Sci. 178, 820 (1986).

"L. A. DeLouise and N. Winograd, Surf. Sci. 159, 199 (1985).

${ }^{7}$ L. H. Dubois, P. K. Hansma, and G. A. Somorjai, J. Catal. 65, 318 (1980).

${ }^{8}$ T. W. Root, L. D. Schmidt, and G. B. Fisher, Surf. Sci. 134, 30 (1983).

"P. Ho and J. M. White, Surf. Sci. 137, 103 (1984).

"1) L. Bugyi and F. Solymosi, Surf. Sci. 188, 475 (1987).

" R. E. Hendershot and R. S. Hansen, J. Catal. 98, 150 (1986).

12J. S. Villarrubia and W. Ho, J. Chem. Phys. 87, 750 (1987).

${ }^{13}$ D. G. Castner and G. A. Somorjai, Surf. Sci. 83, 60 (1979)

${ }^{14}$ G. L. Kellogg, J. Phys. (Paris) 48, 233 (1987)

${ }^{15}$ N. Kruse, G. Abend, and J. H. Block, J. Chem. Phys. 91,577 (1989).

"J. H. Block and A. W. Czanderna, in Methods and Phenomena, edited by A. W. Czanderna (Elsevier, Amsterdam, 1975), Vol. I, p. 379.

${ }^{17}$ N. Kruse, G. Abend, and J. H. Block, J. Chem. Phys. 88, 1307 (1988).

${ }^{1 \times}$ H. A. C. M. Hendrickx, and B. E. Nieuwenhuys, Surf. Sci. 175, 185 (1986).

${ }^{11}$ N. Kruse and J. H. Block, Stud. Surf. Sci. Catal. 30, 173 (1987)

${ }^{20}$ H. F. J. van 't Blik, J. B. A. D. van Zon, T. Huizinga, J. C. Vis, D. C. Koningsberger, and R. Prins, J. Phys. Chem. 87, 2264 (1983); J. Am. Chem. Soc. 1073139 (1985).

${ }^{21}$ D. B. Liang, G. Abend, J. H. Block, and N. Kruse, Surf. Sci. 126, 392 (1983). 